\title{
Bounds for some entropies and special functions
}

\author{
AdinA BĂRAR ${ }^{1}$, GABRIELA RALUCA MOCANU $^{2}$ and IOAN RAŞA ${ }^{1}$
}

\begin{abstract}
.
We consider a family of probability distributions depending on a real parameter and including the binomial, Poisson and negative binomial distributions. The corresponding index of coincidence satisfies a Heun differential equation and is a logarithmically convex function. Combining these facts we get bounds for the index of coincidence, and consequently for Rényi and Tsallis entropies of order 2.
\end{abstract}

Acknowledgements. GM is partially supported by a grant of the Romanian Ministry of National Education and Scientific Research, RDI Programme for Space Technology and Advanced Research - STAR, project number 513, 118/14.11.2016.

\section{REFERENCES}

[1] Abel, U., Gawronski, W. and Neuschel, Th., Complete monotonicity and zeros of sums of squared Baskakov functions, Appl. Math. Comput., 258 (2015), 130-137

[2] Adell, J. A., Lekuona, A. and Yu, Y., Sharp bounds on the entropy of the Poisson Law and related quantities, IEEE Trans. Information Theory, 56 (2010), 2299-2306

[3] Berdysheva, E., Studying Baskakov-Durrmeyer operators and quasi-interpolants via special functions, J. Approx. Theory, 149 (2007), 131-150

[4] Gavrea, I. and Ivan, M., On a conjecture concerning the sum of the squared Bernstein polynomials, Appl. Math. Comput., 241 (2014), 70-74

[5] Ger, R. and Nikodem, K., Strongly convex functions of higher order, Nonlinear Anal., 74 (2011), 661-665

[6] Gould, H. W., Combinatorial identities, Morgantown, W. Va. (1972)

[7] Harremoës, P., Topsøe, F., Inequalities between entropy and index of coincidence derived from information diagrams, IEEE Trans. Information Theory, 47 (2001), 2944-2960

[8] Heilmann, M., Erhöhung der Konvergenzgeschwindigkeit bei der Approximation von Funktionen mit Hilfe von Linearkombinationen spezieller positiver linearer Operatoren, Habilitationsschrift, Universität Dortmund, 1992

[9] Merentes, N. and Nikodem, K., Remarks on strongly convex functions, Aequat. Math., 80 (2010), 193-199

[10] Nikolov, G., Inequalities for ultraspherical polynomials. Proof of a conjecture of I. Raşa, J. Math. Anal. Appl., 418 (2014), 852-860

[11] Raşa, I., Unpublished manuscripts (2012)

[12] Raşa, I., Special functions associated with positive linear operators, arxiv: 1409.1015v2 (2014)

[13] Raşa, I., Rényi entropy and Tsallis entropy associated with positive linear operators, arxiv: 1412.4971v1 (2014)

[14] Raşa, I., Entropies and the derivatives of some Heun functions, arxiv: 1502.05570v1 (2015)

[15] Raşa, I., Entropies and Heun functions associated with positive linear operators, Appl. Math. Comput., 268 (2015), 422-431

[16] Raşa, I., Complete monotonicity of some entropies, Period. Math Hung. DOI 10.1007/s10998-016-0177-5

[17] Raşa, I., The index of coincidence for the binomial distribution is log-convex, arXiv: 1706.05178 [math.CA]

[18] Rényi, A., On measures of entropy and information, in Proc. Fourth Berkeley Symp. Math. Statist. Prob., Vol. 1, Univ. of California Press, 1961, pp. 547-561

[19] Simic, S., Jensen's inequality and new entropy bounds, Appl. Math. Lett., 22 (2009), 1262-1265

[20] Tsallis, C., Possible generalization of Boltzmann-Gibbs statistics, J. Stat. Phys., 52 (1988), 479-487

[21] Ţăpuş, N. and Popescu, P. G., A new entropy upper bound, Appl. Math. Lett., 25 (2012), 1887-1890

Received: 26.06.2017; In revised form: 15.01.2018; Accepted: 22.01.2018

2010 Mathematics Subject Classification. 94A17, 33E30, 33C05, 33C45.

Key words and phrases. Probability distribution, entropies, Heun functions, logarithmically convex functions.

Corresponding author: Gabriela Raluca Mocanu; gabriela.mocanu@academia-cj.ro 
[22] Wagner, M., Quasi-Interpolaten zu genuinen Baskakov-Durrmeyer-Typ Operatoren, Shaker Verlag, Aachen, 2013

[23] Yu, Y., Complete monotonicity of the entropy in the central limit theorem for gamma and inverse Gaussian distributions, Stat. Prob. Lett., 79 (2009), 270-274

1 TeChNical University of Cluj-Napoca

DEPARTMENT OF MATHEMATICS

Memorandumului 28, 400114 Cluj-NAPOCA, Romania

E-mail address: el lena_sontica@yahoo.com

E-mail address: ioan.rasa@math.utcluj.ro

2 Romanian Academy, Cluj-Napoca Branch

ASTRONOMICAL INSTITUTE

Cireşilor 19, 400487 Cluj-NAPOCA, Romania

E-mail address: gabriela.mocanu@academia-cj.ro 